\title{
Pumping Rates for Water Drainage in the Main Ring Tunnne1: Scale Considerations of the SSC
}

\section{E. A. Treadwe 11}

March 1984

I. Introduction

II. Data (Pump Run Time Readings)

III. Results and Conclusions

\section{Introduction}

The Fermilab site has water bearing, geologic units distributed uniformly above a flat bedrock surface. These units, i.e. glacial tills, sands, and gravels are seasonably fed by fluctuations in rainfall and melting snow. Since the overall site topography is flat, ground water settles, often saturates the soil, and creates a challenge to the relatively dry requirements of the accelerator tunnel. Subsurface pumping of the water is achieved by the operation of online sump pumps (see Fig. 1), one pump in each of the 24 service buildings which access the tunnel. Drainage overflows are exhausted into a network of interconnected ponds.

The objective of this note is to calculate the pumping rate for water drainage in the Main Ring Tunnel, correct for statistical and engineering fluctuations, and to discuss pumping requirements on the SSC scale. 
II. Data

Pump Run Time Readings

$\begin{array}{lcccc}\text { Building } & \text { Reading A } & & \text { Reading B } & \text { Total Run Time } \\ \text { A1 } & 25029.9 & & 25751.3 & 721.4 \\ \text { A2 } & 88999.5 & & 89762.0 & 762.5 \\ \text { A3 } & 79149.3 & & 79429.4 & 280.1 \\ \text { A4 } & 69531.3 & 69863.7 & 332.4 \\ \text { B1 } & - & - & \text { dark tunne1 }(602.5) \\ \text { B2 } & 91046.6 & 91046.6 & \text { dead meter }(408.2) \\ \text { B3 } & 08633.6 & 09207.7 & 574.1 \\ \text { B4 } & 65223.3 & 65659.0 & 436.7 \\ \text { C1 } & 21551.3 & 22022.8 & 471.5 \\ \text { C2 } & 10317.1 & 10773.7 & 456.6 \\ \text { C3 } & 67937.9 & 68324.9 & 387.0 \\ \text { C4 } & 67980.9 & 68253.0 & 272.1 \\ \text { D1 } & 82629.7 & 82859.9 & 230.2 \\ \text { D2 } & - & - & \text { dead meter }(561.3) \\ \text { D3 } & 09077.9 & 09582.4 & 504.5 \\ \text { D4 } & 33811.0 & 33811.0 & \text { dead meter }(173.4) \\ \text { E1 } & 79720.7 & 81133.3 & 1412.6 \\ \text { E2 } & 70695.4 & 70794.5 & 99.1 \\ \text { E3 } & 23741.1 & 25869.4 & 2128.3 \\ \text { E4 } & 88043.7 & 88562.1 & 518.4 \\ \text { F1 } & 07006.7 & 07730.5 & 723.8 \\ \text { F2 } & 06891.9 & 07543.1 & 651.2 \\ \text { F3 } & - & - & \text { dead meter }(617.9) \\ \text { F4 } & 92049.5 & 92528.3 & 478.8\end{array}$

Reading A represents time in minutes and was recorded at $2100,2 / 17 / 84$. Reading $B$ represents time in minutes and was recorded at $0900,2 / 28 / 84$, or 10.5 days later.

dark tunnel represents the conditions which prevented this reading from being recorded.

dead meter is an obvious description.

Note!! The total run times were estimated for B1, B2, D2, D4, and F3 with the mean values and standard deviations calculated for each region A, B, C, D, E, and $F$.

$$
\begin{aligned}
& B 1=\left\langle t_{B}\right\rangle+\sigma \\
& B 2=\left\langle t_{B}\right\rangle-\sigma \\
& D 2=\left\langle t_{D}\right\rangle+\sigma \\
& D 4=\left\langle t_{D}\right\rangle-\sigma \\
& \text { F3 }=\left\langle t_{F}\right\rangle
\end{aligned}
$$


III Results and Conclusions

Each sump pit has a floor area of $20 \mathrm{ft}^{2}$ and a depth of $6 \mathrm{ft}$. There is an underdrain pipe approximately $3 \mathrm{ft}$ above the floor which routes water into the pit and eventually into the ponds. The best estimate for the pumping speed is $(125 \pm 62.5) \mathrm{ft}^{3} / \mathrm{min}$, where the $\pm 50 \%$ error represents pump impellar variations around the tunnel, variations in the water lift distances, and the discharge line impedances. ${ }^{1}$

Calculate the volume of water pumped in 10.5 days by all 24 sumps:

$$
\begin{aligned}
\mathrm{R}(\text { gallons } / \mathrm{hr}) & =\left(125 \pm 62.5 \mathrm{ft}^{3} / \mathrm{min} .\right)(7.5 \mathrm{gal} . / \mathrm{ft})\left(60 \mathrm{~min} \cdot / \mathrm{hr}_{\bullet}\right) \\
& =(\text { between } 28,125 \text { and } 84,375 \mathrm{gallons} / \mathrm{hr} \cdot) \\
\mathrm{V}(\text { gallons }) & =\mathrm{R}\left(\text { gal. } / \mathrm{hr}_{.}\right)(13804.7 \mathrm{~min} .)(0.0167 \mathrm{hr} . / \mathrm{min} \cdot) \\
& =\text { (between } 6,483,895 \text { and } 19,451,685 \mathrm{gallons})
\end{aligned}
$$

Drainage into the tunnel appears to be under control with more than adequate pumping available. Water levels in the pits are comparable and depend on meteorological and pump systematics. Intermittent measurements should be taken of the pump run times and qualitative observations made of moisture in the tunne1. When combined with other tunnel histories, we can better understand drainage as a function of depth, hydrogeology, and tunnel construction materials.

The SSC scale could be an order of magnitude greater than the Main Ring; therefore the pumping requirements could scale with ring size or remain the same with modified pumps, i.e. ten times the sump pit volume and pumping speed. If the hydrogeology differs for both sites or SSC overlaps with the Fermilab site, then the pumping requirements would be considerably less than a factor of ten. 


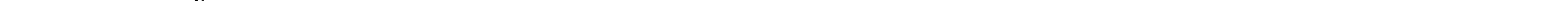

